\title{
Geotechnical approach to stope and pillar optimisation at Granny Smith Mine
}

\author{
L Machuca Gold Fields Australia Pty Ltd, Australia \\ M Sutton Gold Fields Australia Pty Ltd, Australia \\ R Grow Gold Fields Australia Pty Ltd, Australia \\ P Andrews Gold Fields Australia Pty Ltd, Australia
}

\begin{abstract}
The initial determination of the rock mass characteristics and its behaviour has been a key parameter to ensure that a safe and economical extraction can be achieved at Granny Smith Gold Mine (GSGM). The objective of this paper is to outline the geotechnical and planning approach that has been followed to ensure that the intended stoping performance is reached. The geotechnical analysis involves the use of geological and structural analysis, empirical design methodologies and numerical analysis/simulation to determine the effects of induced stresses on the overall stability of the open stopes as well as to the adjacent excavations. Stope and pillar design, size and placement are optimised with the aim to maximise extraction without compromise to personnel safety and global mine stability. The reinforcement requirements for accesses and adjacent excavations to the stoping areas are determined at the planning stage with the aid of numerical modelling.
\end{abstract}

\section{Introduction}

In early 2014, Gold Fields Australia aimed to increase ore recovery and reduce internal stope dilution at GSGM. This led to a shift in focus for both mine design and geotechnical practices at the operation. To achieve a reduction in internal dilution the geotechnical approach required review of design process to enable less conservative stoping to be undertaken. Utilising a number of new strategies such as more developed numerical modelling, the effective radius factor (ERF) method and detailed back-analysis, the geotechnical approach to stope stability analysis became more comprehensive and a decrease of $10 \%$ in internal dilution was achieved.

\section{Background}

\section{$2.1 \quad$ Location and geology}

The Wallaby gold deposit is located in the Laverton Greenstone belt of the Eastern Goldfields in Western Australia, approximately $700 \mathrm{~km}$ northeast of Perth and $27 \mathrm{~km}$ south of Laverton (Figure 1). The upper section of the Wallaby gold deposit was successfully extracted by open pit mining methods, with the pit reaching a terminal depth of $205 \mathrm{~m}$ in 2007. 


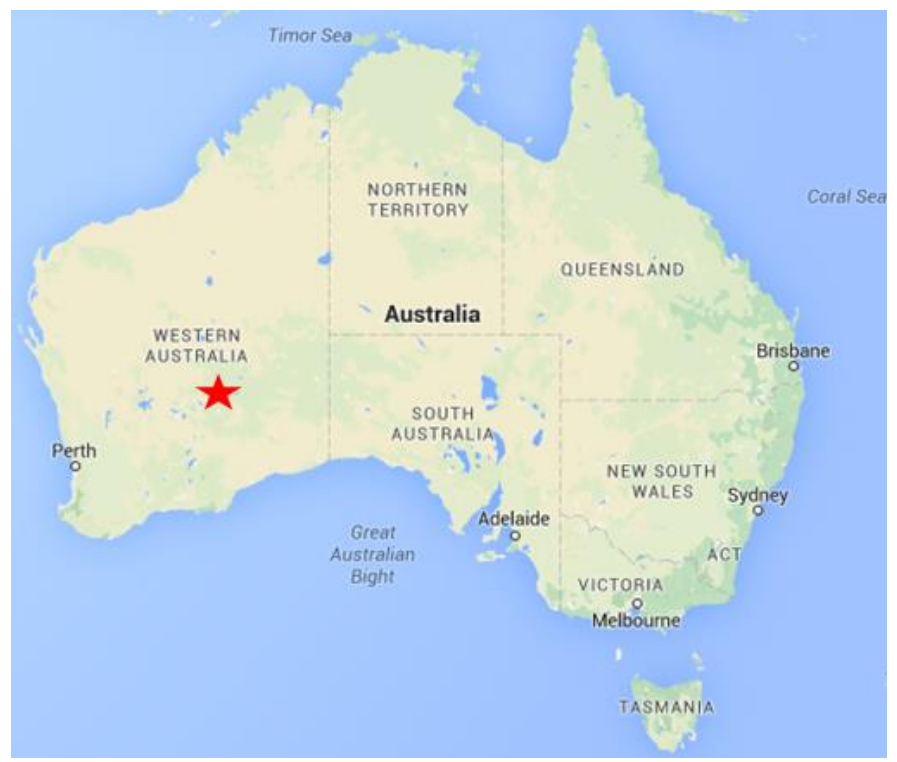

\section{Figure 1 Wallaby deposit location}

The Wallaby gold deposit consists of at least eight sub-horizontal ore lodes that are spaced approximately $100 \mathrm{~m}$ apart (vertically) and dip $<10^{\circ}$ towards $045^{\circ}$. The general orebody geometry is shown in Figure 2 . The ore lodes average $2 \mathrm{~m}$ thick ranging from 0.5 to $>10 \mathrm{~m}$ in thickness, and are situated within a pipe-like zone of magnetite-actinolite alteration which forms a 500 to $600 \mathrm{~m}$ wide pipe plunging at $50^{\circ}$ towards $185^{\circ}$. The deposit also includes thinner, higher grade linking structures of gold mineralisation which typically dip $20^{\circ}$ towards $035^{\circ}$. These high grade cross-linking structures are linked to the emplacement of a Syenite intrusion suite (Gold Fields Australia 2011). The sub-horizontal lodes have been termed as Zones 60, 70, 80, 90, 100 and 110 .

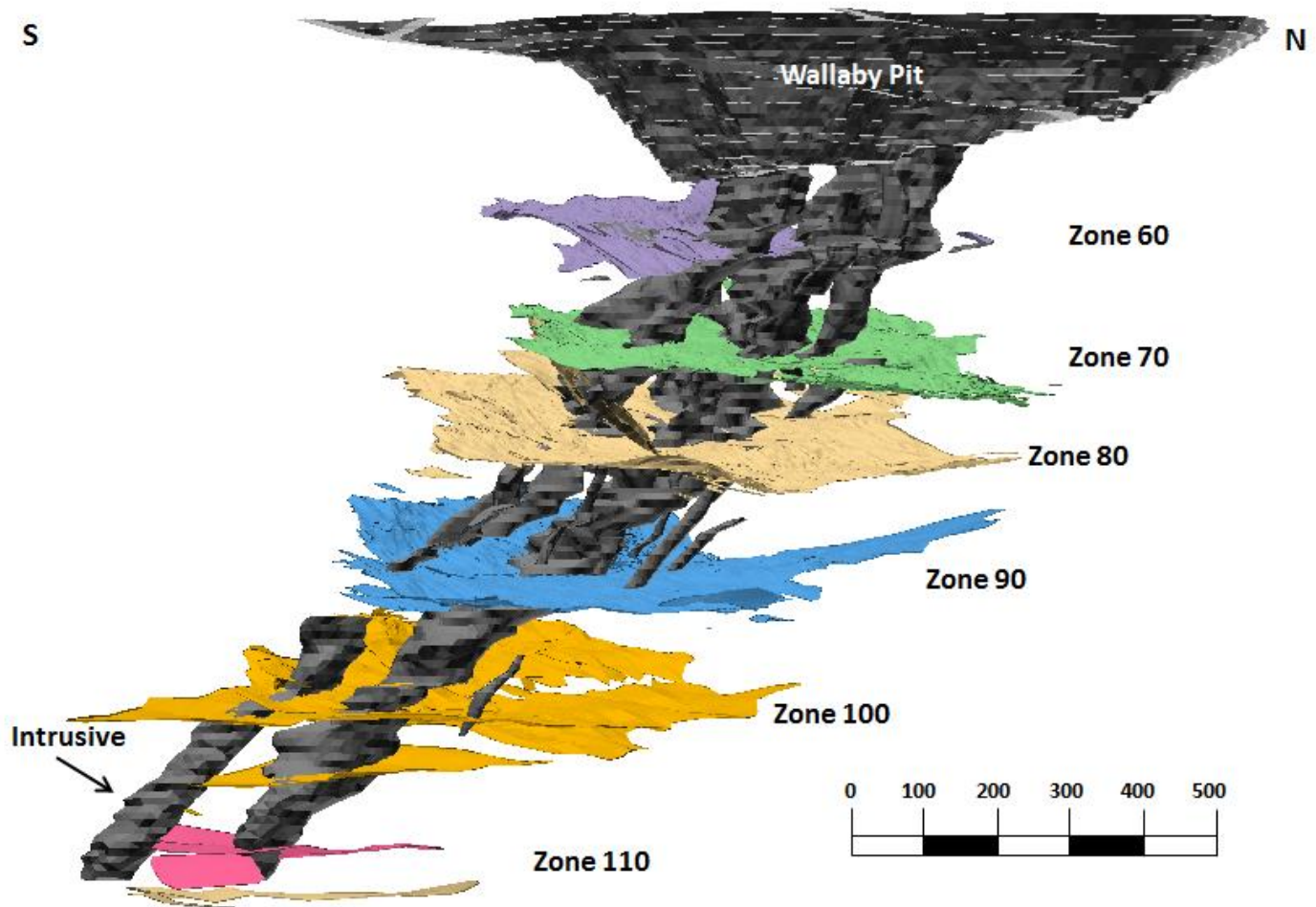

Figure 2 Isometric view of Wallaby showing the flat-lying and steeper ore lodes - as labelled: the intrusive syenite core and the Wallaby open pit, looking west 


\subsection{Mining methods}

Mining methods at GSGM are based on variations of a longhole open stope and room and pillar method. There is no planned backfill. This methodology was originally proposed due to the flat lying nature of the ore lodes.

The mining methods used are:

- Inclined room and pillar.

- Transverse longhole open stoping.

- Longhole wall slash.

An additional mining method which is locally referred to as 'bulk' is being carried out for mining multiple lodes (lenses) that are in close proximity (Gold Fields Australia 2013).

\section{$2.3 \quad$ Access}

Underground mine access is via a portal established within the completed Wallaby open pit. The main access to the mining areas is by a $5.2 \times 5.7 \mathrm{~m}$ arch profile decline.

The mine is currently designed to exploit five of the stacked mineralised lodes (Zones 60, 70, 80, 90 and $100)$ which extend to a depth of $1.1 \mathrm{~km}$. The lodes are divided into these five zones.

Typically, exploitation of the ore lodes progresses top-down. Multiple stoping panels have and will be extracted from each lode; therefore, barrier/regional pillars have been used to separate stoping blocks (Rauert 2012).

The standard development dimensions used underground are summarised in Table 1.

Table 1 Underground development dimensions

\begin{tabular}{ccccc}
\hline \multirow{2}{*}{ Lode } & $\begin{array}{c}\text { Development } \\
\text { type }\end{array}$ & \multicolumn{2}{c}{ Dimensions } & Profile \\
& Wecline/access & 5.2 & 5.7 & Arched \\
\multirow{2}{*}{ Z60-Z80 } & Ore drive & 4.6 & 4.6 & Arched \\
& Decline/access & 5.2 & 5.7 & Arched \\
\multirow{2}{*}{ Z90 } & Ore drive & 4.6 & 4.6 & Arched \\
& Decline/access & 5.2 & 5.7 & Arched \\
\multirow{2}{*}{ Z100 } & Ore drive & 4.6 & 4.6 & Arched \\
& &
\end{tabular}

Historically, the ground support systems installed at GSGM have been designed to manage static loading conditions. However, as the mining has progressed with increasing depth below surface, the effects of stress have become more evident with an increase in seismic activity and strain deformation around excavations.

Given these considerations, an increase in ground support capacity was determined for the $Z 90$ and Z100 ore lodes to manage higher levels of deformation and dynamic loading. Table 2 summarises the primary ground support requirements. 
Table 2 Primary ground support for underground development

\begin{tabular}{cccc}
\hline Lode & Bolt type & Length $(\mathrm{m})$ & Surface support \\
\hline \multirow{2}{*}{ Z70-Z80 } & Resin bolt & 2.4 & $50 \mathrm{~mm}$ thick fibre-reinforced shotcrete \\
& G.0 m off from floor
\end{tabular}

\section{Stope design}

Post 2014 input from the geotechnical engineers into the stope design process at early stages has been paramount to ensuring potential geotechnical issues that could affect the overall stability have been identified and, where possible, mitigated to reduce their effects on stope performance. Each new stoping block undergoes both preliminary and conceptual designs. The designs are prepared by the planning engineers with input from the geotechnical team.

\subsection{Preliminary stope block design}

The initial stope design process begins after the orebody delineation has been finalised by the geology department. Accesses to ore areas and preliminary stope geometries are designed by mine planning engineers. The geotechnical department then performs a preliminary geotechnical stability assessment of these layouts.

The primary outcome of this initial geotechnical assessment is to determine if there is any potential for global instability issues associated with extraction and interaction of the newly designed stoping block with adjacent mining areas and capital infrastructure.

\subsubsection{Large-scale structures}

One of the most significant structures impacting the operation is the 'Wedge Shear' which is a zone containing multiple shears through several lodes. A second important structural feature is the Syenite Pipe, a volcanic intrusive which is located in the central area of the ore lodes and can be characterised as being stiffer rock than the conglomerate host rock.

These major structures are reviewed in 3D space to identify their proximity to designed stoping panels, which allows of the estimation of potential adverse effects on stability.

\subsubsection{Global stability (Abaqus)}

The determination of the global rock mass response to mining is analysed using a non-linear discontinuum finite element numerical modelling prepared by Beck Engineering, the model is re-run and updated after new lode extensions have been delineated and all the geometries of the extracted stopes are input. The numerical outputs (Figure 3) are utilised to determine the areas that could be negatively affected by significant levels and rates of strain deformation due to the planned mine developed and extraction. 


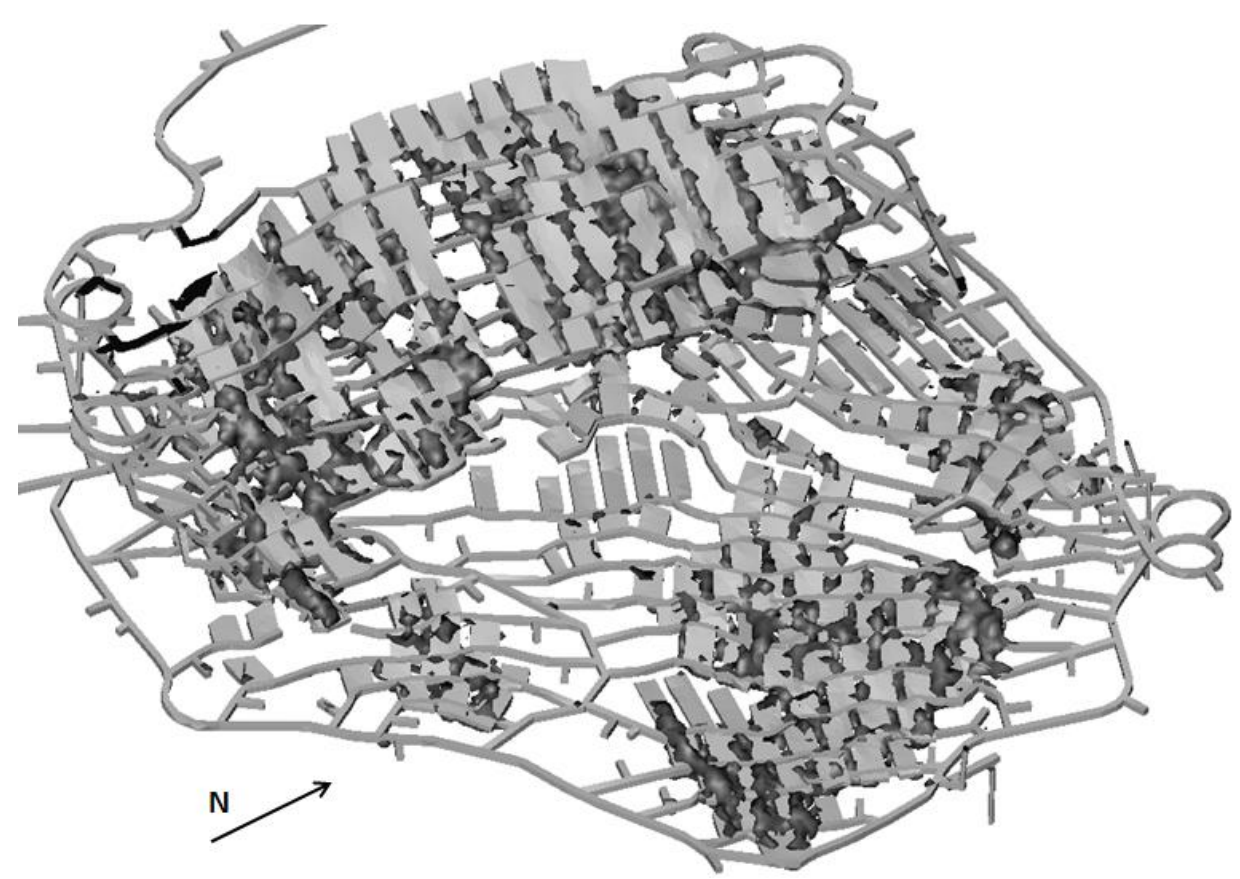

Figure 3 Numerical modelling results showing strain deformation within z90 lode

\subsubsection{Ground support strategy}

The numerical models allow evaluation of the rate energy release (RER) and the seismogenic potential in the areas of interest. This aids in designing appropriate ground support systems specific for each lode.

As part of the preliminary analysis the size and location of barrier pillars is also reviewed to ensure capital infrastructure is protected. In addition, the review of stope dimensions and their geometry is evaluated to highlight any rib or island pillar requirements. This metadata is used to assess the preliminary economics of the stoping block and allows for iterative re-design prior to the commencement of mining occurring.

\subsection{Conceptual stope design}

After the accesses to the orebody have been excavated, the geology department conducts infill grade control diamond drilling with the objective of validating grades and tonnage, and to improve orebody delineation. After the geological model has been released, the planning department prepares and evaluates the 'final' conceptual stope designs.

Geotechnical personnel conduct a detailed assessment of the conceptual designs. The main focus of this work is to review the stability of each individual stope in more detail and to assess the interaction between surrounding stopes, pillars and adjacent excavations. The assessment uses several empirical methodologies such as the stability graph (Mathews et al. 1980), critical span determination (Lang et al. 1991) and ERF (Milne et al. 1996), to determine the stability of the proposed stopes based upon the proposed mining sequence.

Finally, the shapes are evaluated using numerical models to determine the global deformation of the stoping blocks using the global non-linear modelling results. Map3D software is also utilised for the analysis of individual stope panels on the basis of sequencing and pillar stability.

\subsubsection{Detailed rock mass characterisation}

Detailed rock mass characteristics for each individual stope are obtained by conducting geotechnical mapping of ore drives (post ground support installation) and geotechnical core logging of oriented drill holes, this information is used for the determination of the geotechnical characteristics of each domain. 
Photo core logging is conducted to review all drill holes that intersect the backs (hanging wall (HW)) of stoping panels. This process helps to identify areas of reduced rock mass quality which may affect the stability of the stopes (Figure 4).

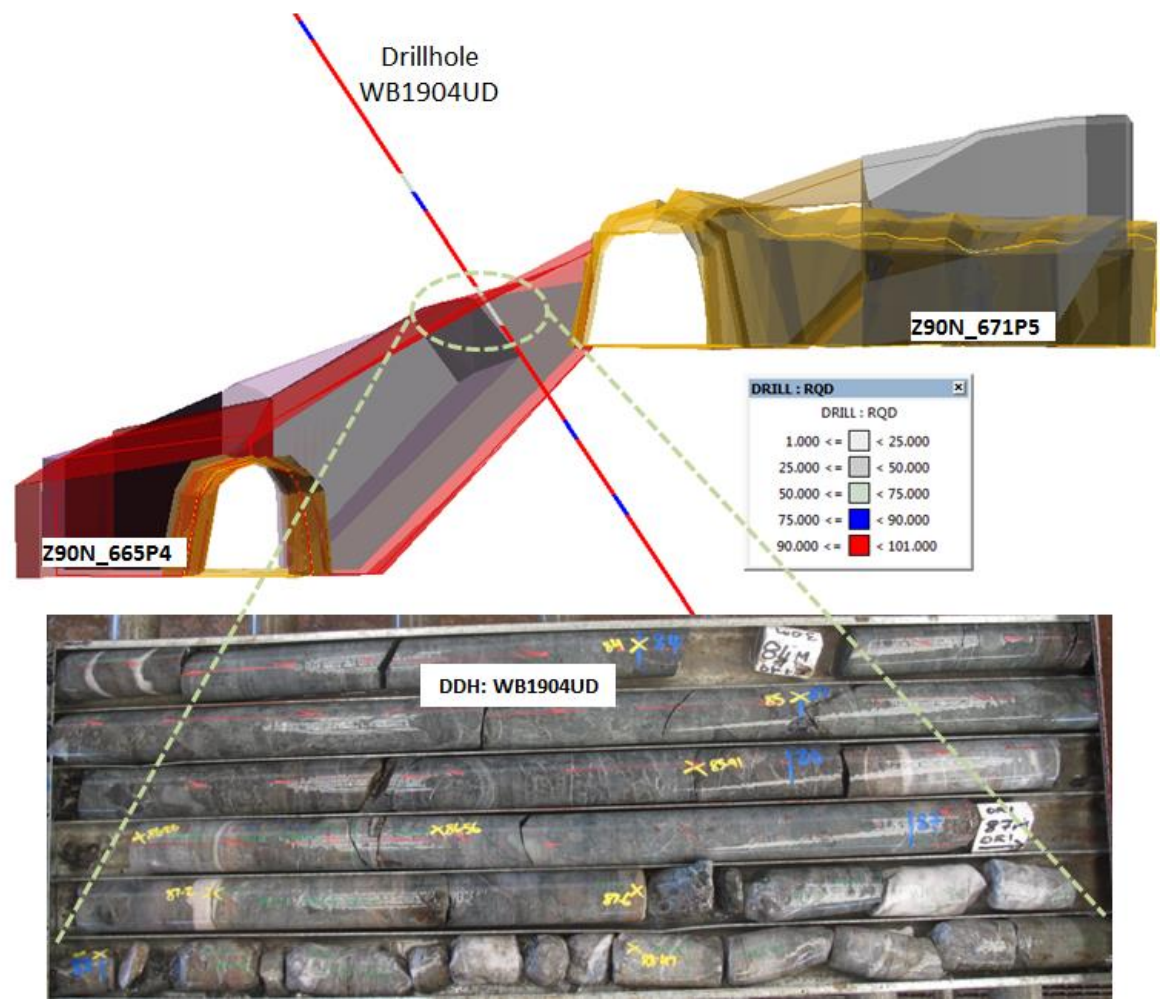

Figure 4 Drill core showing fractured rock at the HW contact in z90 671-665 stopes

Block models have been developed for the different stoping blocks within the mine allowing for evaluation of the rock quality designation (RQD) (after Deere 1964) values of the rock. The primary objective of these models is to identify zones of low \% RQD within the HW contact and to determine if these areas of low RQD could negatively affect the stability of the stopes (Figure 5 ).

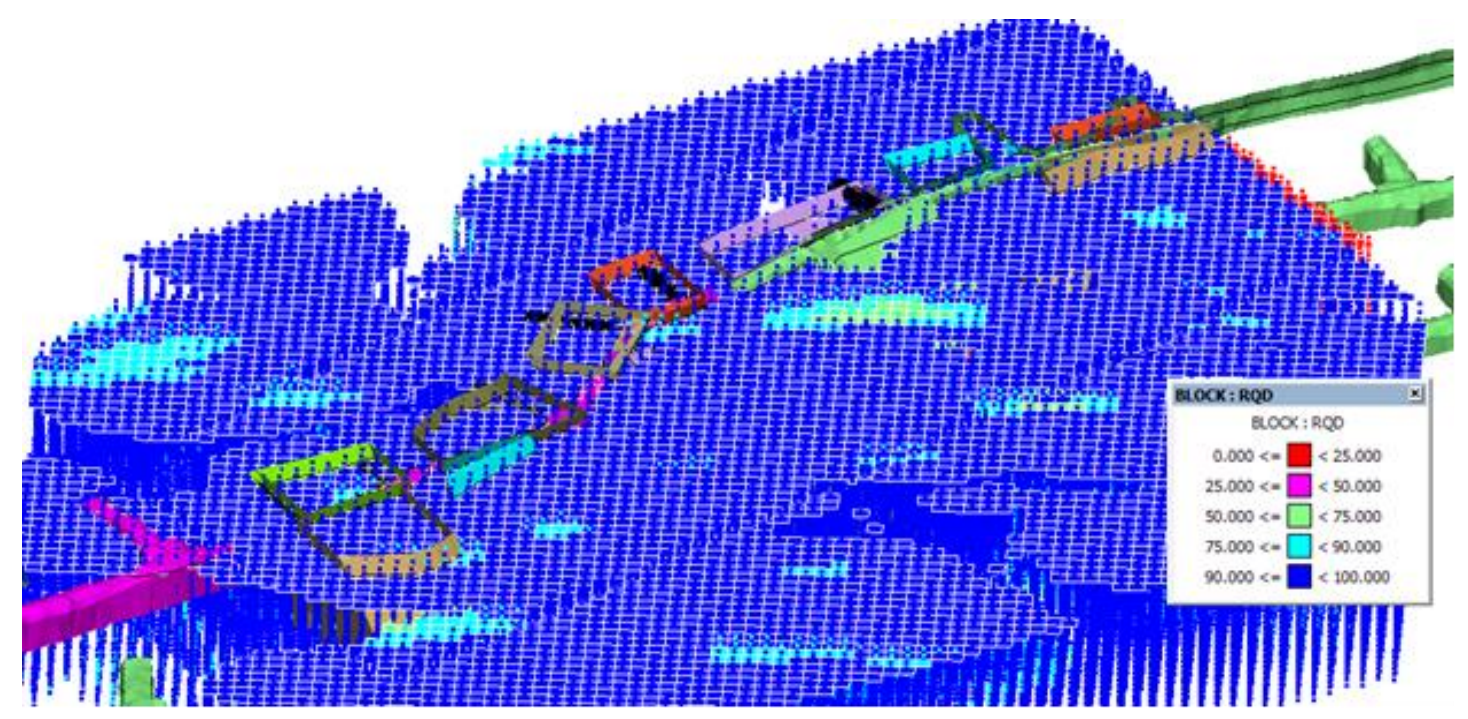

Figure 5 RQD block model

The Norwegian Geotechnical Institute (NGI) rock tunnelling quality index Q' method (after Barton 1974) has been used to determine the rock mass characteristics for the stope stability assessment and for the 
determination of ground support requirements. The following table (Table 3 ) shows the summary of the $Q$ and $Q^{\prime}$ values obtained for the different domains.

Table $3 \quad Q^{\prime}$ and $Q$ values of the underground geotechnical domains

\begin{tabular}{|c|c|c|c|c|c|c|c|c|c|c|c|}
\hline \multirow{2}{*}{ Domain } & \multicolumn{5}{|c|}{$\mathbf{Q}^{\prime}$} & \multicolumn{5}{|c|}{$\mathbf{Q}$} & \multirow{2}{*}{$\begin{array}{l}\text { Sample } \\
\text { number }\end{array}$} \\
\hline & Ave & SD & 25th & 50th & 75th & Ave & SD & 25th & 50th & 75th & \\
\hline Conglomerate & 36.2 & 4.0 & 16.6 & 25.0 & 47.5 & 4.5 & 4.0 & 2.0 & 3.0 & 5.8 & 103 \\
\hline Ore zone & 78.0 & 43.2 & 38.4 & 89.0 & 107.0 & 15.3 & 8.5 & 7.5 & 17.4 & 21.0 & 15 \\
\hline Conglomerate/ore & 49.4 & 25.9 & 30.2 & 48.8 & 50.0 & 6.1 & 3.2 & 3.7 & 6.0 & 6.2 & 48 \\
\hline Syenite & 42.6 & 22.9 & 26.8 & 36.6 & 50.0 & 9.1 & 4.9 & 5.7 & 7.8 & 10.6 & 26 \\
\hline
\end{tabular}

The intact rock properties and in situ stresses are used as input parameters for the calculations of the rock mass properties and numerical analyses. Table 4 shows a summary of the intact rock test properties for the different rock types at GSGM.

The in situ stresses at GSGM have been determined using the Western Australian School of Mines acoustic emission (AE) methods and are shown in Table 5.

Table 4 Intact rock testing results

\begin{tabular}{ccccccc}
\hline Rock type & $\begin{array}{c}\text { Uniaxial } \\
\text { compressive } \\
\text { strength } \\
\text { (MPa) }\end{array}$ & $\begin{array}{c}\text { Uniaxial } \\
\text { tensile } \\
\text { strength } \\
\text { (MPa) }\end{array}$ & $\begin{array}{c}\text { Young's } \\
\text { modulus E } \\
\text { (GPa) }\end{array}$ & $\begin{array}{c}\text { Secant } \\
\text { Poisson's } \\
\text { Ratio }\end{array}$ & $\begin{array}{c}\text { Cohesion } \\
\text { (MPa) }\end{array}$ & $\begin{array}{c}\text { Friction } \\
\text { angle } \\
\left({ }^{\circ}\right)\end{array}$ \\
\hline $\begin{array}{c}\text { Syenite } \\
\text { intrusive }\end{array}$ & 230 & 15.1 & 67.7 & 0.39 & 30.1 & 61 \\
& 302 & 15.4 & 66.4 & 0.29 & 30.8 & 67 \\
\hline Ore zone & 298 & 10.6 & 61.3 & 0.27 & 21.2 & 61 \\
& 291 & 12.8 & 69.5 & 0.35 & 25.7 & 70 \\
& 288 & 14.1 & 74.4 & 0.39 & 28.2 & 68 \\
\hline \multirow{2}{*}{ Conglomerate } & 1317 & 17.3 & 60.7 & 0.47 & 34.6 & 65 \\
& 135 & 13.4 & 85.3 & 0.33 & 30.1 & 41 \\
\hline & 240 & 14.8 & 62.7 & 0.34 & 29.6 & 55 \\
\hline
\end{tabular}

Table 5 Principal in situ stress magnitudes

\begin{tabular}{cccc}
\hline $\begin{array}{c}\text { Principal stress } \\
\text { (MPa) }\end{array}$ & Equation & $\begin{array}{c}\text { Bearing } \\
\left.\mathbf{(}^{\circ}\right)\end{array}$ & $\begin{array}{c}\text { Plunge } \\
\left.\mathbf{(}^{\circ}\right)\end{array}$ \\
\hline$\sigma_{1}$ & $0.0517 \times \operatorname{depth}(\mathrm{m})+7.5$ & 301 & 01 \\
$\sigma_{2}$ & $0.0397 \times \operatorname{depth}(\mathrm{m})$ & 031 & 05 \\
$\sigma_{3}$ & $0.0261 \times \operatorname{depth}(\mathrm{m})$ & 196 & 85 \\
\hline
\end{tabular}




\subsubsection{Stoping block stability assessment}

A detailed stability assessment for each individual stope panel and its interaction with adjacent stopes and excavations is conducted. The potential constrains that could affect the stope performance are identified and involve orebody and stope geometry, lithological contacts, geological structures, the effects of the stress redistribution, seismic activity and drill and blast practices.

\subsubsection{Empirical design methods}

Empirical design methodologies are used at GSGM to assist with predicting the overall stability of stope blocks. The main methodologies used at Granny Smith are:

- Modified stability graph method (Mathews et al. 1980).

- Maximum critical span (Lang et al. 1991).

- Effective Radius Factor (Milne 1997).

\subsubsection{Stope analysis}

Individual stope stability assessment is then carried out with the aim to economically maximise ore recovery without compromising stability.

\subsubsection{Stability graph method}

The stability graph method by Mathews et al. (1980) and modified by Potvin (1988) and Nickson (1992) has been widely used at GSGM to aid in the prediction of the overall stability of stopes. The modified stability number $\mathrm{N}^{\prime}$ is calculated for the backs of each stope based on the stope's rock mass characteristics. The resultant $\mathrm{N}^{\prime}$ values are then plotted against the hydraulic radius (HR).

The overall classification of the rock mass at GSGM has been categorised to be of good quality.

The HR values of designed stopes are obtained by measuring the combined stopes geometries that will merge during mining following the proposed extraction sequence.

Figure 6 illustrates the HR and N' values of designed stopes within the Z90 lode, whereby values are plotted into the stability graph which includes the Nickson (1992) curve. The majority of the stopes sit into the transition and unstable section of the graph. It is important to note HR values do not take secondary reinforcement into consideration.

The stability graphs have been prepared by lode to account for the varying conditions of depth and rock mass. This enables comparative analysis of new designs with those previously extracted within the same lode, helping to determine if stope optimisation can take place or if a risk to instability exists. 


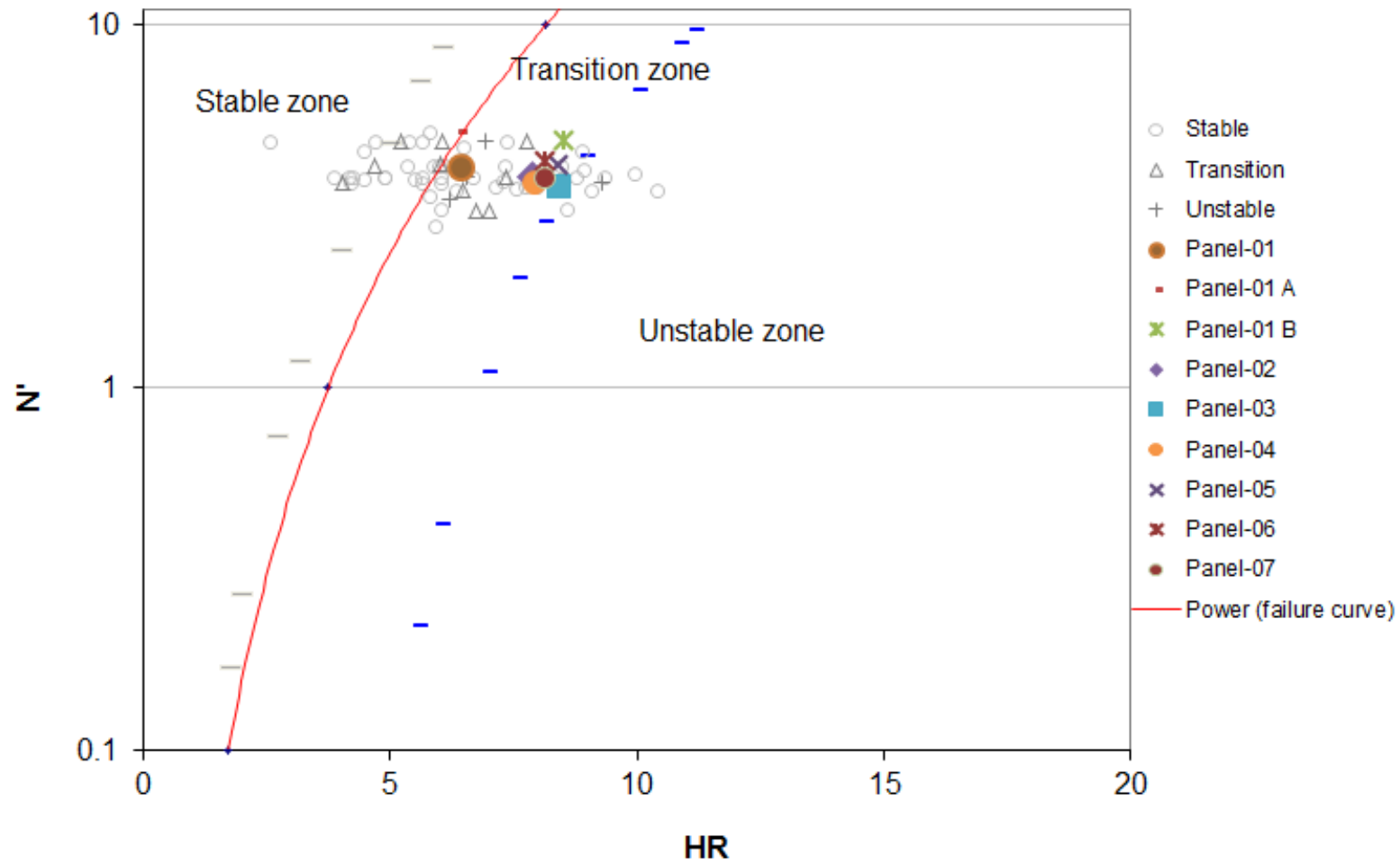

Figure 6 Design HW stability graph for stopes in Z90 lode

\subsubsection{Critical span}

The critical span methodology has been used to determine the maximum dimensions of the spans inside the stope. This method utilises the maximum diameter circle that can be drawn within the boundaries of the stope and its internal pillars. Figure 7 illustrates the schematic of a stoping block and pillar layout and the critical spans within the stopes.

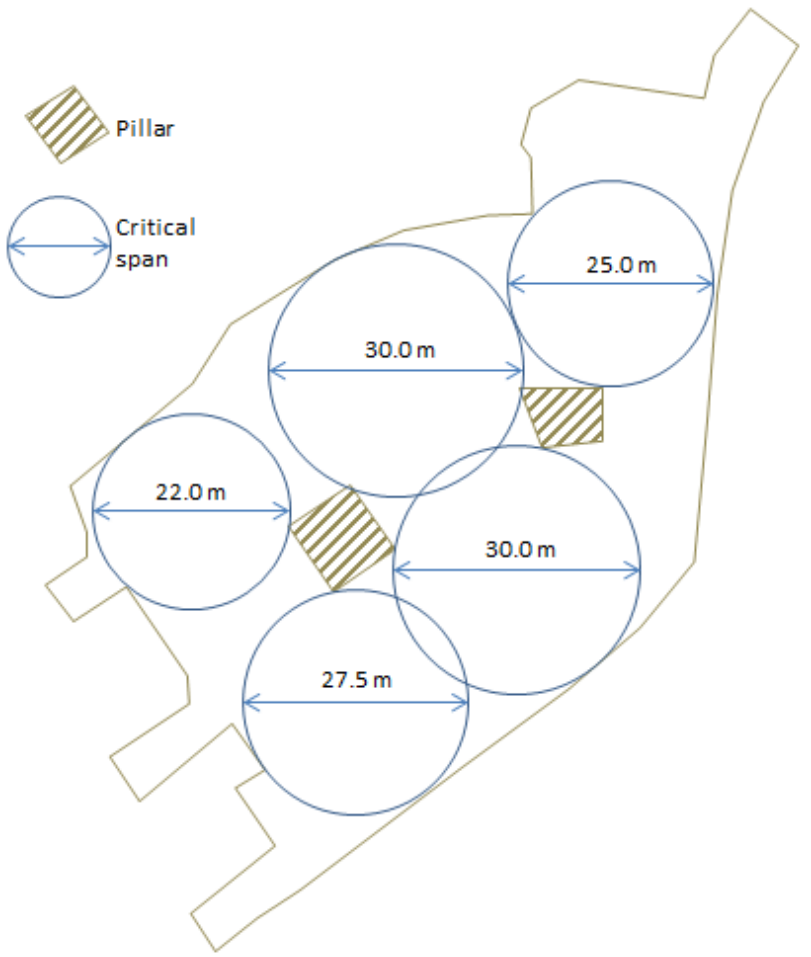

Figure 7 Critical span within stope Z90 N 676-665 
The performance of the stopes can be quantified by plotting the measured depth of failure versus critical stope span (Villaescusa 2004). This methodology aims to identify potentially unstable stopes due to size, whereby pillars may be required or stope dimensions reduced to provide more stability. Conversely, the opportunity arises to increase stope dimensions where values plot in known stable zones within the graph which are based on historical back-analysis data.

\subsubsection{Effective radius factor}

The ERF has been used to conduct a more detailed HR calculation of the mining geometries. The ERF was developed with the purpose of improving the assessment of complex mining geometries (Milne \& Pakalnis 1997).

The methodology used at Granny Smith to calculate the ERF of stopes is based on the extraction sequence whereby the calculated dimensions are obtained from the combined geometries as the extraction sequence advances.

The program written by Lunder (1994) to quantify the ERF has been used to compute the ERF calculation process. A macro was written to be utilised with AutoCAD ${ }^{\circledR}$ software for the evaluation of ERF. The results produce a grid-based map overlain by the ERF contours that are visualised using the program Surfer ${ }^{\circledR}$.

Figures 8,9 and 10 illustrate the results of the ERF determination based on the mining sequence for the proposed Z9ON 676-655 mining block. It is possible to observe the evolution in the increase in dimension, helping to determine when a specific dimension has been reached and, at that point in the sequence, determine if the need for a pillar or extra reinforcement exists.

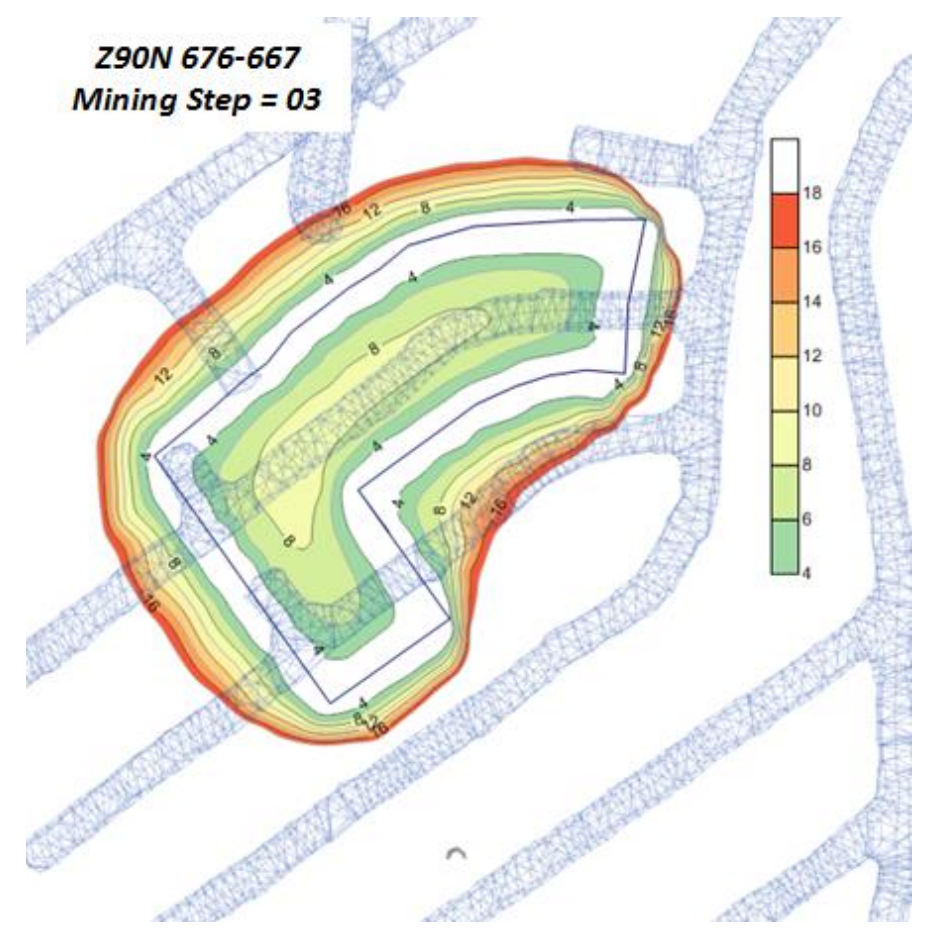

Figure 8 ERF analysis for Z90N 676-655 stope block after mining step 3 


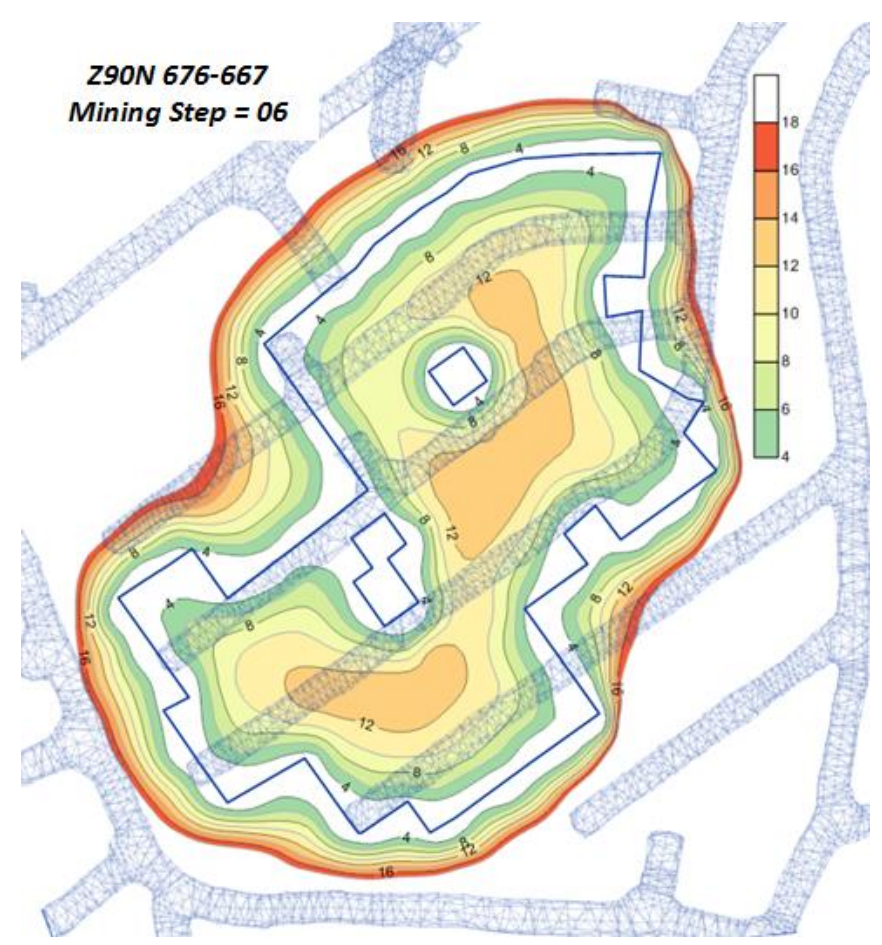

Figure 9 ERF analysis for Z90N 676-655 stope block after mining step 6

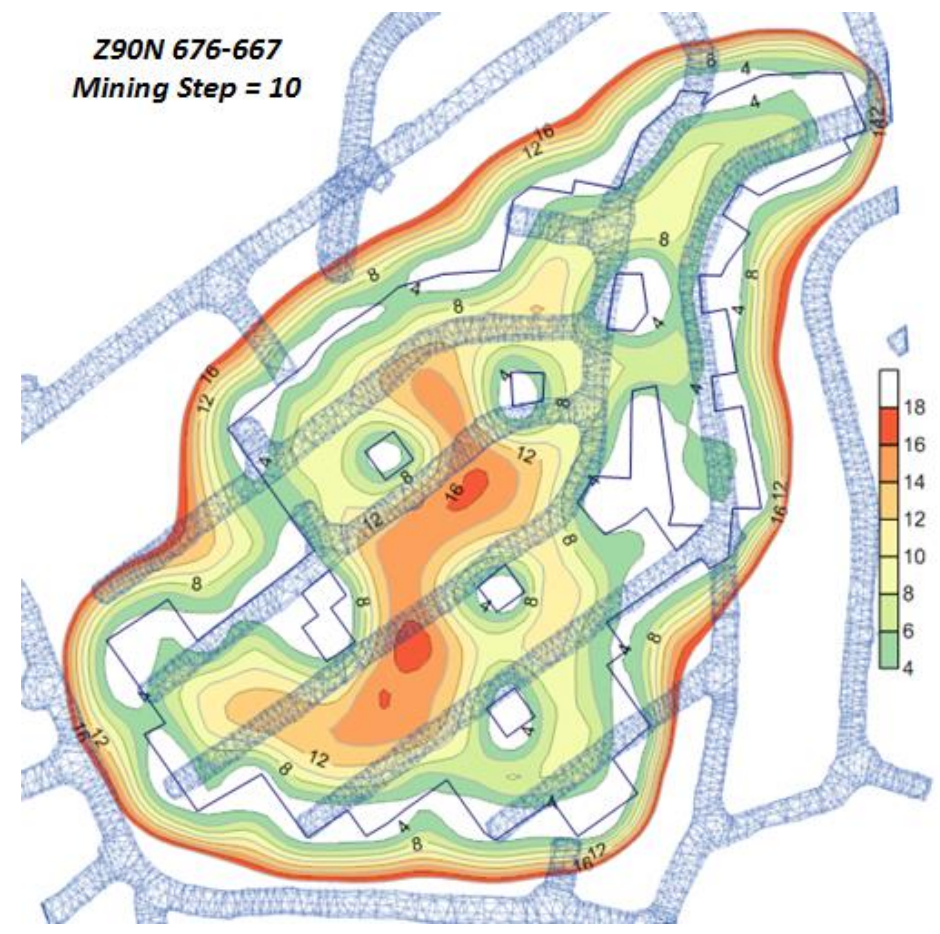

Figure 10 ERF analysis for Z90N 676-655 stope block after full extraction

ERF values are then plotted against $\mathrm{N}^{\prime}$ and the measured depth of failure for further evaluation of stope performance (Figure 11). 


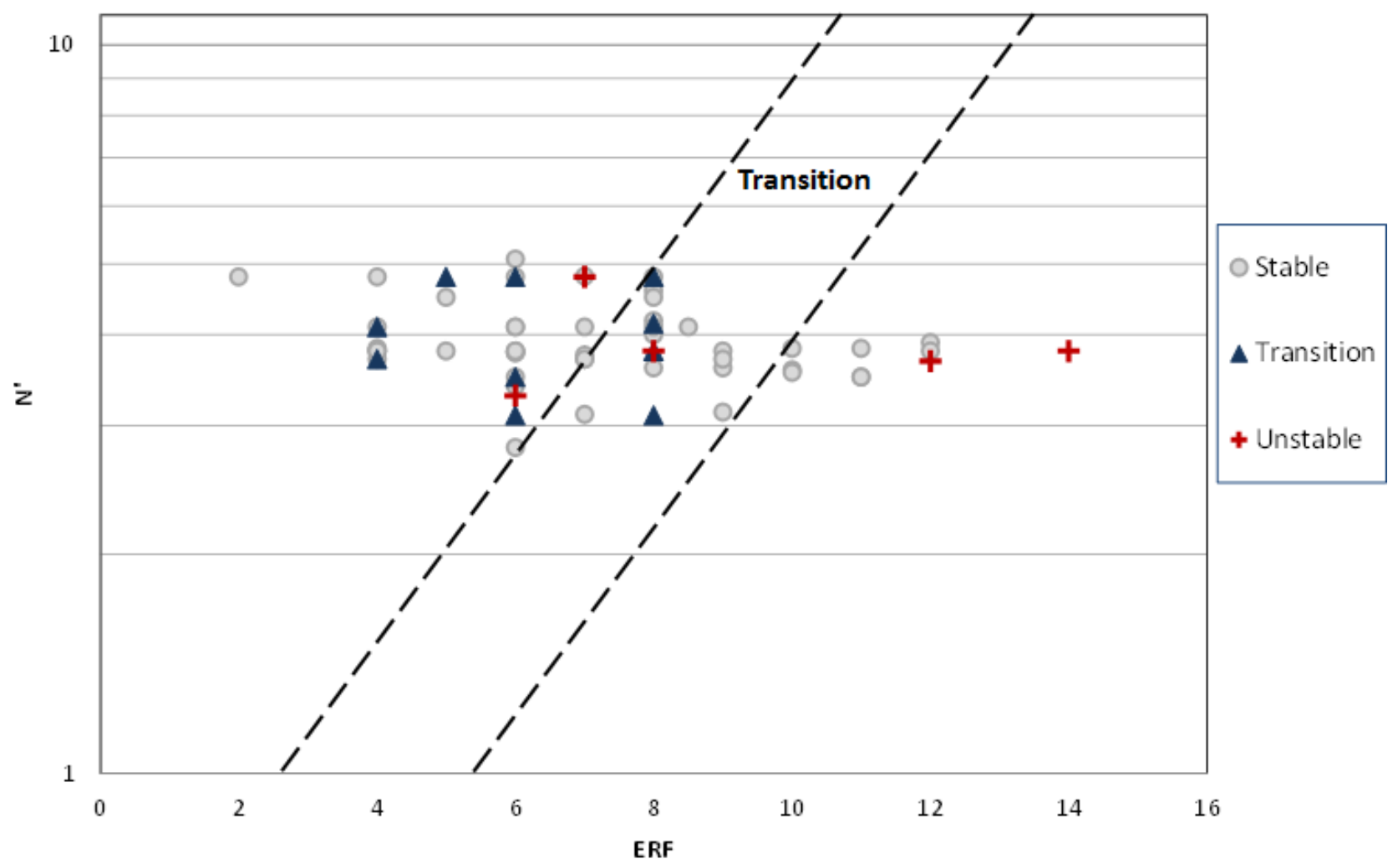

Figure 11 Effective radius factor versus N' z90 lode

\subsubsection{Pillar design}

Pillars are essential to the overall stability of the stoping areas at GSGM. Due the sub-horizontal nature of the orebody a decision was made not to use backfill at the mine. For that reason, pillars play an integral role in ensuring that safe and stable open stopes are created and regional stability is maintained.

Stability analyses for all pillars are conducted using a combination of empirical methods as outlined by Lunder (1994), using the tributary area. Pillars are also analysed using Map3D and non-linear numerical models.

Pillar location is designed based on a variety of factors: span or ERF dimensions, length of stope, the need to reduce large ERF where panels combine, and economic considerations.

Pillars performance is back-analysed to calibrate future stability criteria. Visual inspections and cavity monitoring survey (CMS) data allow calibration, which in turn aids the revision of designed parameters for future pillar design.

\subsubsection{Extraction sequence}

The mining sequence can influence ore recovery, extraction ratios, ore dilution and level of rehabilitation required in the development excavations.

In order to manage these effects, mining sequences are evaluated using geotechnical techniques to optimise ore extraction whilst minimising dilution, without compromise to safety. Numerical modelling has been used to aid with the estimation of the influence of mining induced stresses and its influence on development excavations, stopes and geological structures.

The extraction sequences for Zone 90 and the future Zone 100 lodes has increased geotechnical constraints due predominantly to faulting and seismic potential (a common condition in associated with deep mining activities). In order to safely manage these effects, the block extraction maintains a scheduled echelon ' $V$ ' shape advancing mining front (Figure 12) (Gold Fields Australia 2011). 


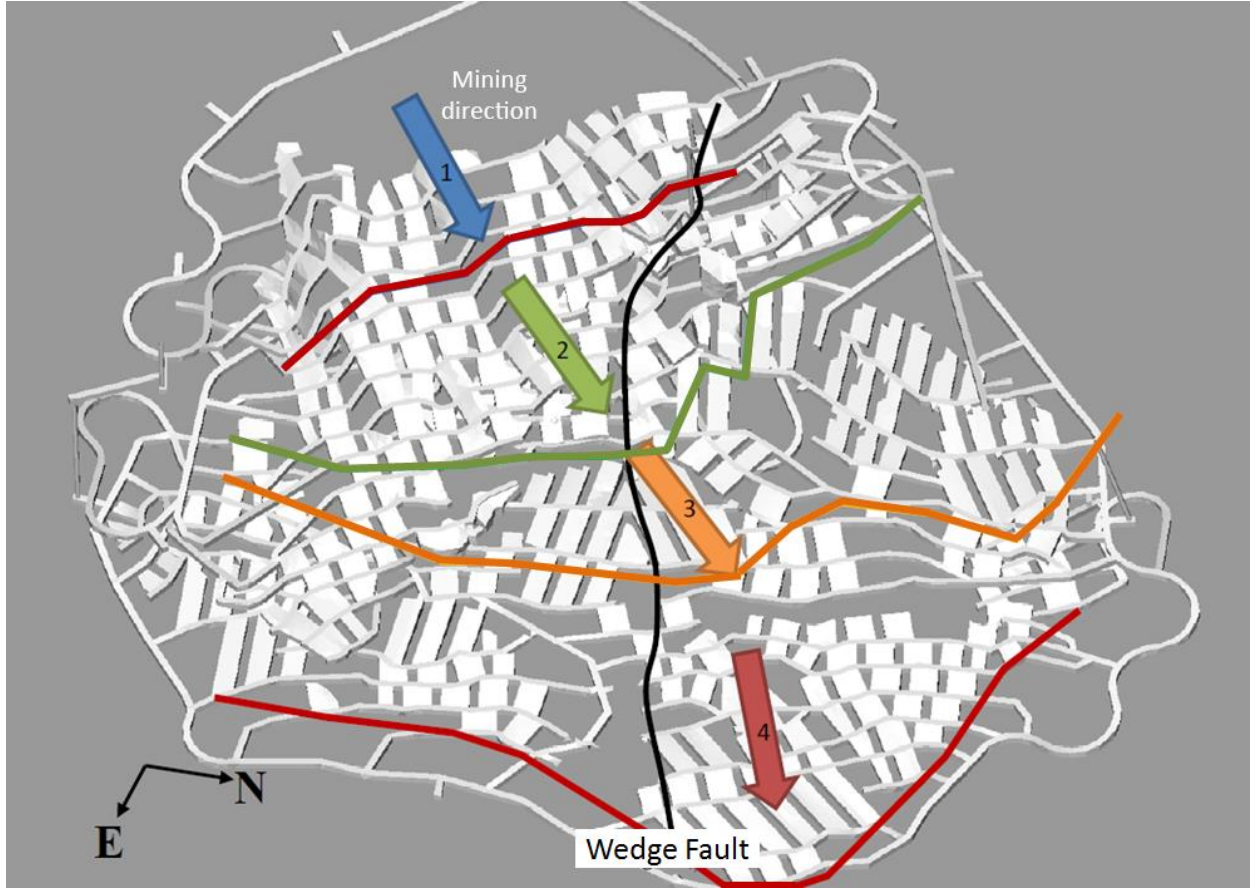

Figure 12 Proposed mining sequence z90 lode

\subsubsection{Numerical modelling}

\subsubsection{Non-linear modelling}

As previously discussed, the determination of the global rock mass response to the stress redistribution has been conducted using non-linear modelling methods. The model results aid in determining areas that may undergo significant levels of strain deformation and higher levels of RER in the form of induced seismicity.

\subsubsection{Linear elastic modelling}

Map3D software has been used to analyse more localised areas of stoping blocks and or pillars. The objective is to analyse the extraction sequence of a panel and the effect that the stress redistribution will have on the stope boundaries and pillars.

Modelling results can help determine the potential depth of failure, secondary ground support requirements, redesign of stope shape (e.g. arching of backs) and the need to reduce HR or critical span through the use of pillar placement.

\subsubsection{Secondary ground support}

The secondary ground support is designed to reinforce the HW of the stope and is conducted at the detailed/conceptual geotechnical analysis stage. The ore drives are reinforced with twin strand cable bolts cement grouted with lengths of $6,9,12$, and, to a lesser extent, $15 \mathrm{~m}$. A cable bolt design is shown in Figure 13. 


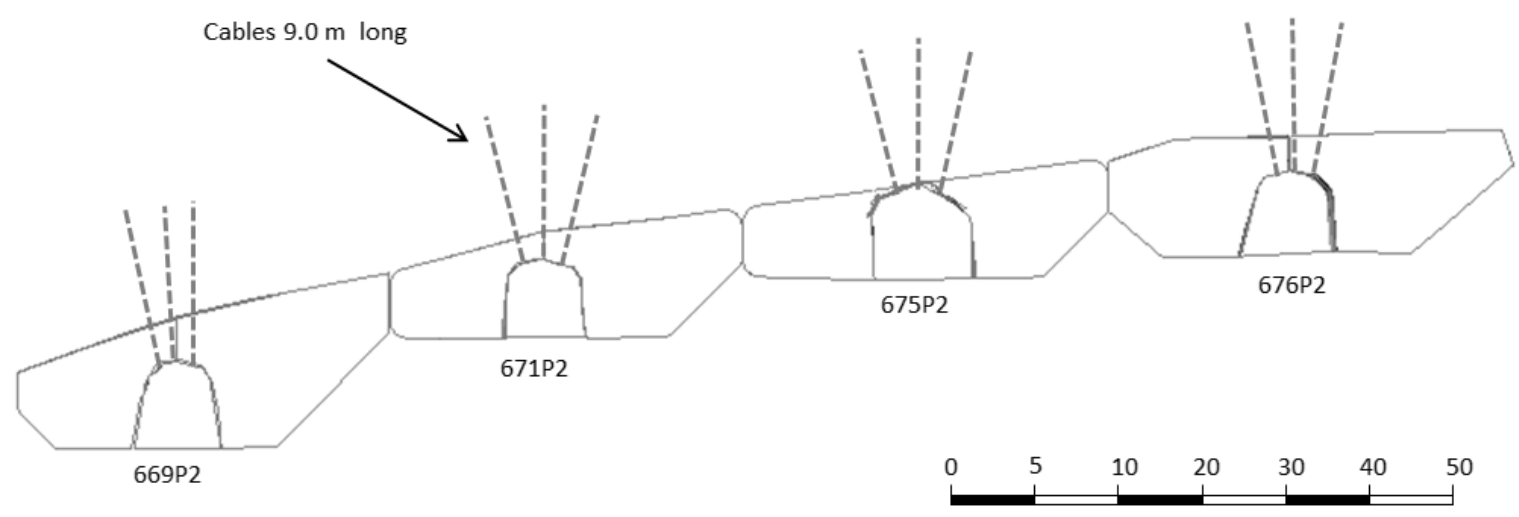

Figure 13 Standard secondary stope reinforcement design stope Z90N 676-669 with $9 \mathrm{~m}$ long cables cross-section looking west

The plate and tensioning of cables is not always possible due to the HW contact being above the backs of the ore drive. In those cases, the lower parts of the cables are blasted through. Measurement and observation indicate that the installed HW cables have been performing well, helping to reduce overbreak by maintaining the confinement within the backs.

Figure 14 shows a down dip view of the fully extracted open stope Z90 676 P2 and P3. The design and final stope shape were superimposed for illustration of the stope performance. The final dimensions of this stope were $H R=9$, critical span $=24$ and $E R F=8.5$.

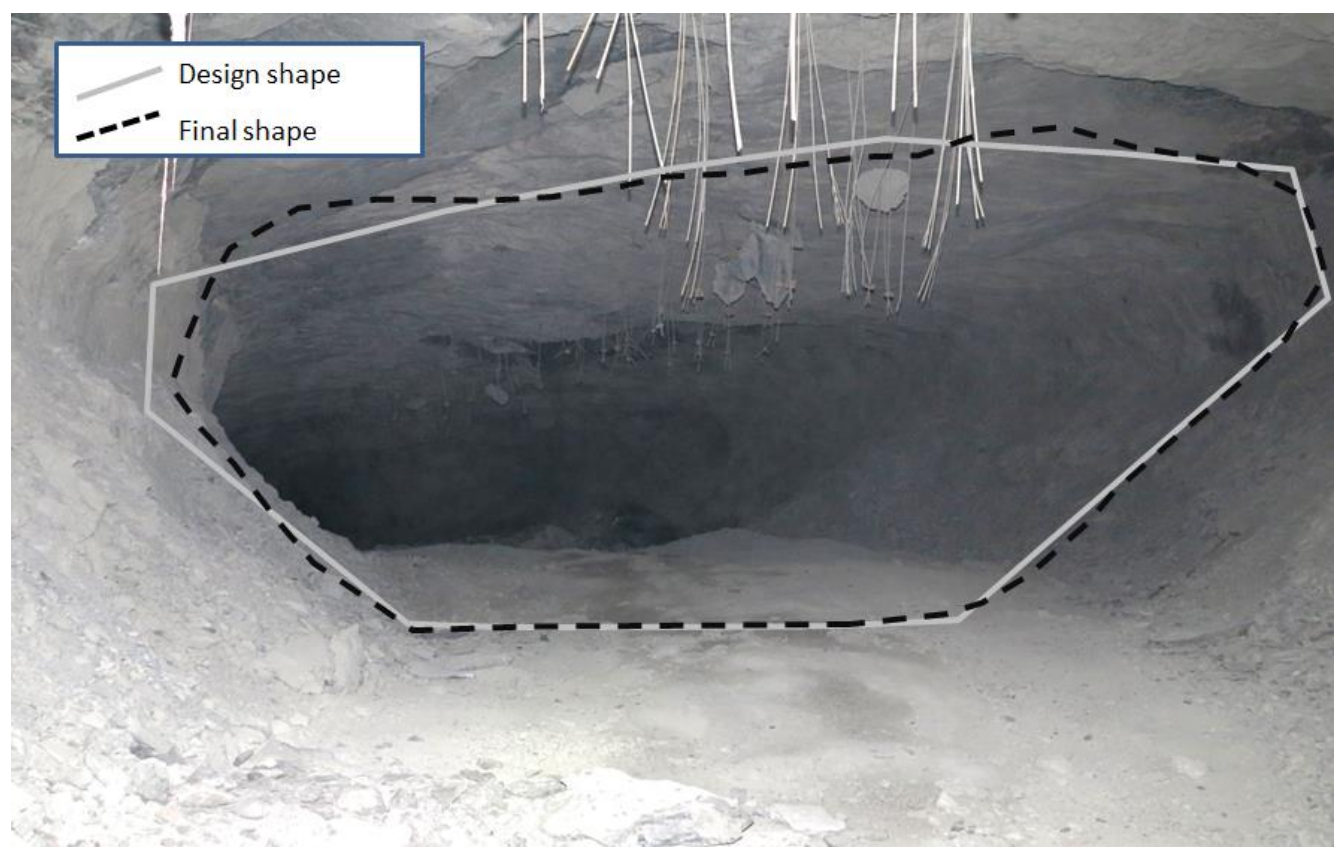

Figure 14 Successful extraction with the use of cable bolts Z90N 676 P2-P3

Brow location and reinforcement are reviewed for every stope. Typically, the ground support consists of a minimum of three $6 \mathrm{~m}$ long twin strand cable bolts and, where more challenging geotechnical conditions are expected, the installation of at least six cables (two rows of three cables) is utilised.

\subsubsection{Drill and blast}

After the stability assessment has been finalised, the drill and blast engineers commence work on the design for the blastholes and firing sequence. The geotechnical engineers are actively involved in providing feedback to the drill and blast engineers throughout this process. 
Figure 15 shows a schematic view of the production drill design, stope shape and the secondary ground support for a planned stope in the Z90 Lode.

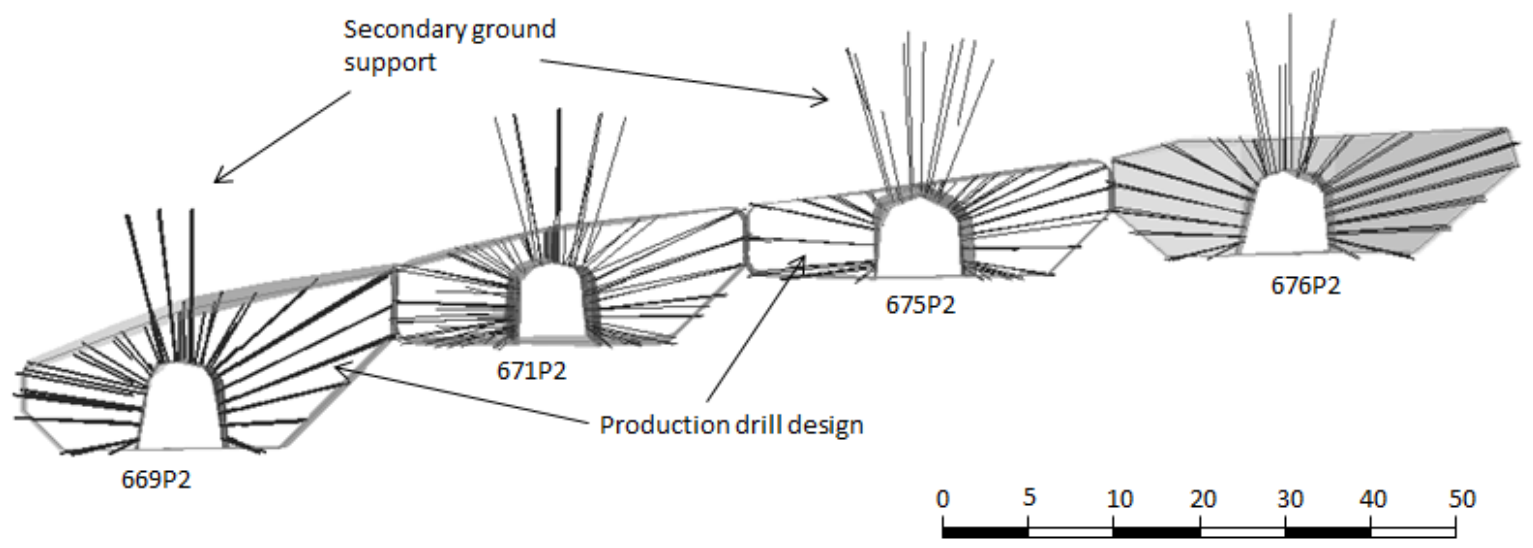

Figure 15 Production drill holes, secondary ground support and stope geometry

\section{$4 \quad$ Stope performance}

The performance of each individual stope is measured after full extraction and, in some cases when large stopes are taken, partial reviews are conducted during extraction. The objective of the performance review is to determine any variations from planned stope design to the final extraction (Villaescusa 2004) and the possible causes that affected the stope performance. The stope performance process is conducted by all departments involved in the design process: geology, planning, drill and blast and geotechnical.

\subsection{Monitoring}

In order to collect data of the stope performance, geotechnical inspections are conducted. The observations are recorded in the production inspection logbook.

The observations made also include ore drive inspections to determine any rock mass damage along the drives adjacent to the stopes. The depth of failure is collected for future model calibration.

The stope HW conditions and pillar performance are reviewed to ascertain whether stability has been maintained and if not, and failure occurred, the mechanism of failure is identified to help determine future controls or modifications to stope and pillar designs. The predominant failure mechanisms observed at GSGM is the formation of wedges and slabs overcome by gravitational forces.

Seismic monitoring takes place at Granny Smith with an increase in the number of significant seismic events becoming evident over time in the deeper areas of the mine. Instances of damage to accesses, stopes and pillars have at times affected production. The increase in induced seismic activity can be directly related to mining activity and the stress redistribution.

The active monitoring of seismic activity has been essential in determining unusual changes in ground response due to mining and the potential effect into the safety of the operational areas. Routine hazard assessments are conducted to evaluate the likelihood of seismic activity occurring, which in turn is used to define re-entry times to production zones.

\subsection{Stope back-analysis}

Back-analysis of the stopes that have been completed in the $Z 90$ level was conducted to measure final stope dimensions (HR, critical span and ERF) and performance so this information can be used for future designs. 
Stope reconciliations are also completed and draw upon the CMS void model of each individual stope prepared by the survey department where deviation from design (overbreak and underbreak) is clearly defined.

The overbreak depth of failure (DoF) is calculated and then plotted against the final stope dimension to provide an indication of stope stability.

The following categories have been used to determine stope performance:

- Stable - depth of failure 0.0 to $2.5 \mathrm{~m}$.

- Transition - depth of failure 2.5 to $4.0 \mathrm{~m}$.

- Unstable - depth of failure $>4.0 \mathrm{~m}$.

Although results from the stability graph indicated the potential for failures and overbreak, only a small number of stopes experienced significant levels of failure (as defined above). It is apparent that the secondary ground support has been effective in helping to maintain the integrity and confinement of the stope backs. However, the full effect of the cable bolts system is not well understood and additional investigation is required.

As previously discussed, the stope performance can be quantified by plotting depth of failure against critical span, HR and ERF values. Figure 16 illustrates the critical span values against depth of failure, although a clear trend has yet to be clearly defined. The largest span that has been successfully excavated in the $Z 90$ is $37 \mathrm{~m}$, with a maximum depth of failure of $1 \mathrm{~m}$.

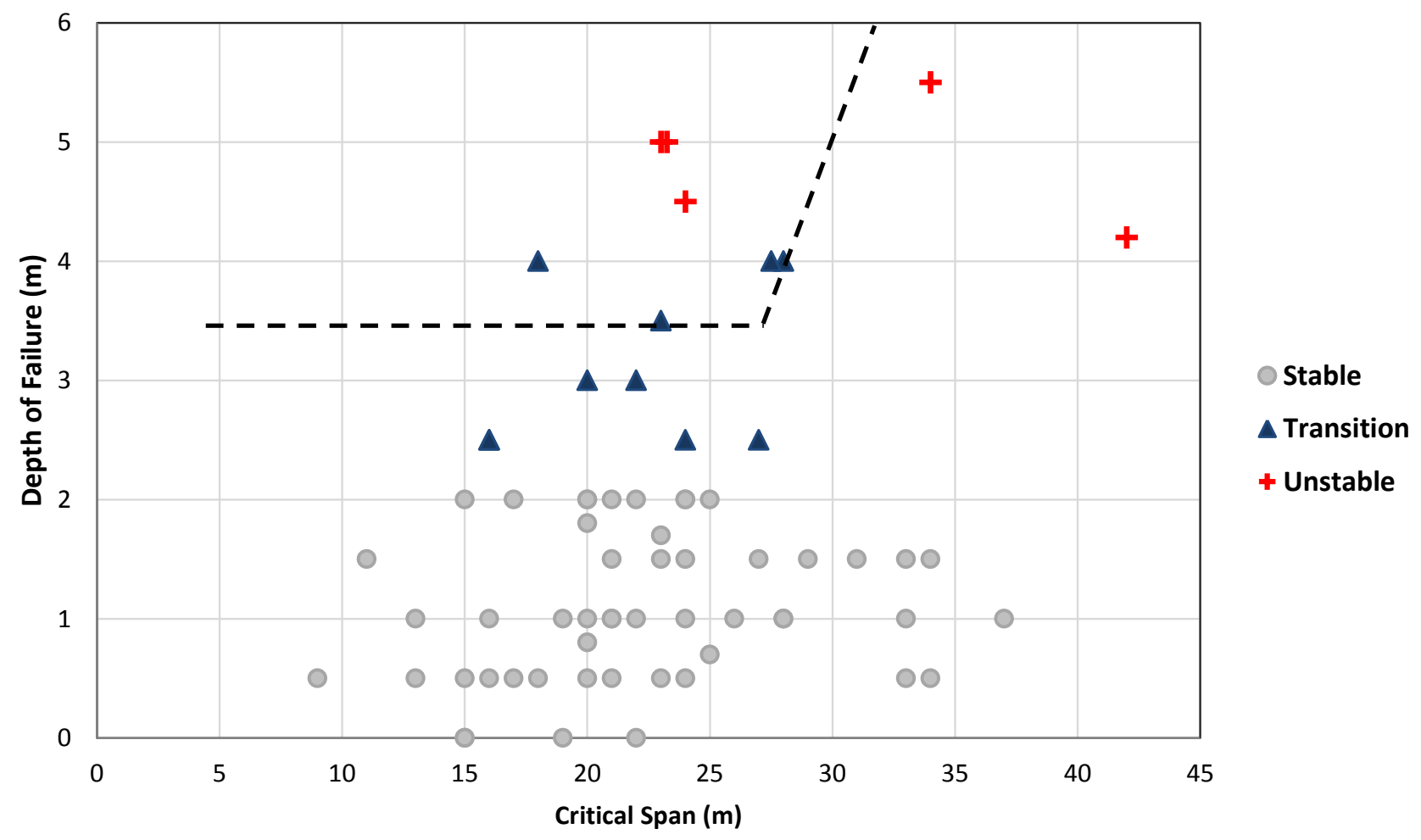

Figure 16 Critical span versus depth of failure - stopes z90 lode

Figure 17 shows the ERF values plotted against the depth of failures with results showing similar trends to the critical span plots; the maximum ERF value that has successfully been excavated was $12 \mathrm{~m}$. 


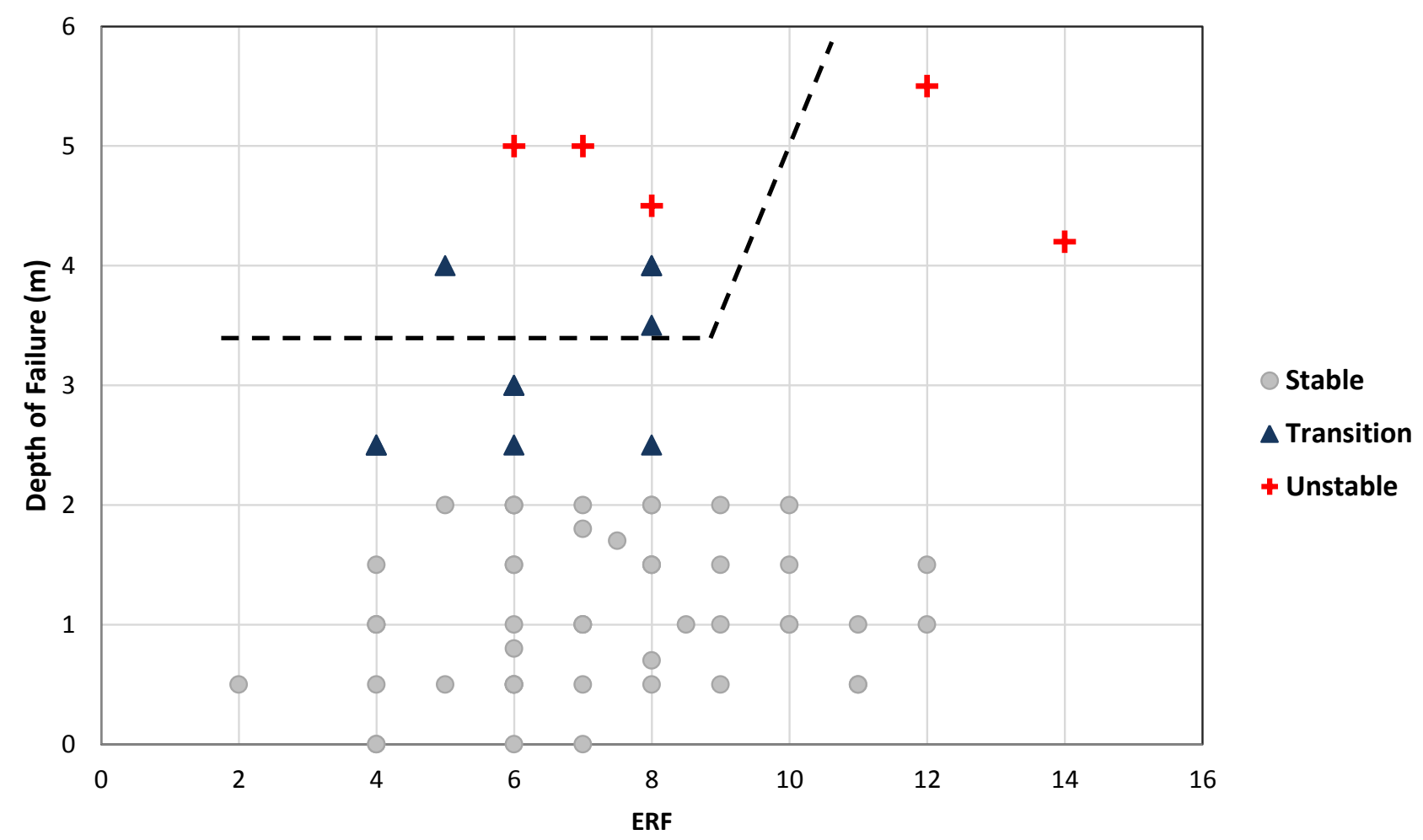

Figure 17 Effective radius factor versus depth of failure - stopes z90 lode

The plots for the HR versus the DoF can be seen in Figure 18. Successful extraction has occurred for a stope with a HR of 10.5 which resulted in a maximum DoF less than $1 \mathrm{~m}$.

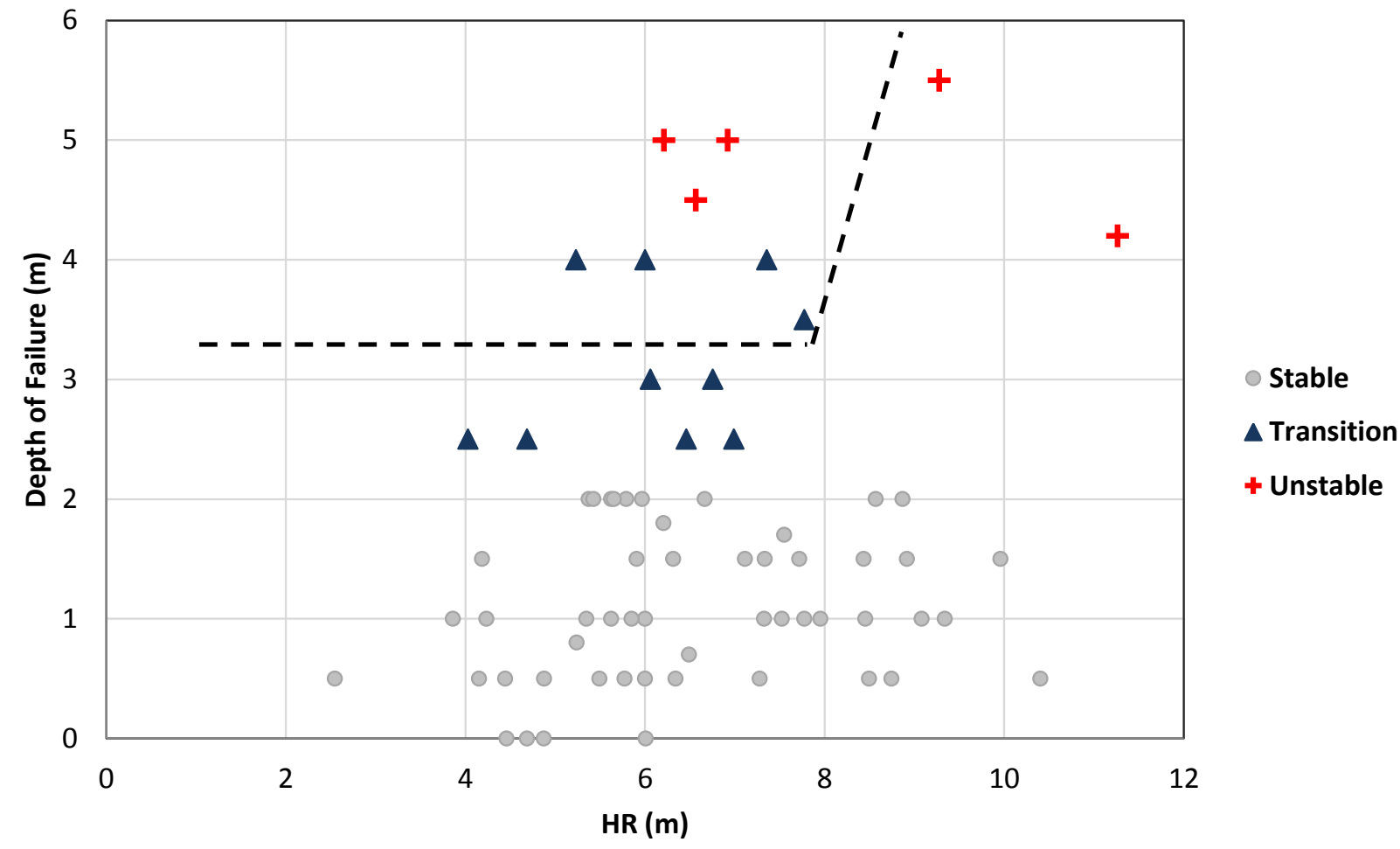

Figure 18 Hydraulic radius versus depth of failure - stopes z90 lode

Back-analysis has identified a combination of defining factors for stopes affected by significant failures such as size of the opening, orientation of the backs with respect to large geological structures, and weak 
lithological HW contacts with shallow angles with respect to the backs of stopes forming slabs and wedges failing due gravitational forces.

As discussed previously, it is important to note that the calculated HR, critical span and ERF values do not take in consideration installed secondary ground support.

\section{Conclusion}

Stope performance can be linked to stope shape and location, and drill and blast design. This performance is assessed during the geotechnical analysis process at which point improvements to both stope stability and extraction can be made.

Due to the extensive nature of geotechnical analysis techniques, GSGM take careful consideration to ensure analyses encompass a comprehensive, systematic and collaborative approach when evaluating stope stability.

Previous back-analysis identified that the earlier design approach had resulted in conservative stope design whereby further extraction may have been achievable. Consequently, future stope designs are now less conservative in regard to stope geometry, dimensions and pillar location when utilised in combination with secondary ground support.

Systematic data collection, analysis and communication within the technical services and operations areas has led to improved stope block and individual stope design at GSGM through an iterative multidisciplinary approach using empirical and analytical methods.

\section{Acknowledgement}

The authors thank Gold Fields Granny Smith for the opportunity to contribute to the symposium.

\section{References}

Barton, N 1974, 'A review of the shear strength of filled discontinuities in rock', Norwegian Geotechnical Institute, no. 105, 38 p.

Deere, DU 1964, 'Technical description of rock cores for engineering purposes', Rock Mechanics and Engineering Geology, vol. 1, no. 1, pp. 17-22.

Gold Fields Australia 2011, Feasibility study: Wallaby Deeps Zone 90, internal report, no. BGS-WAD-FS-001, Gold Fields Australia, Perth.

Gold Fields Australia 2013, Feasibility study: Granny Smith Zone 100, internal report, Gold Fields Australia, Perth.

Lang, B, Pakalnis, R \& Vongpaisal, S 1991, 'Span design in wide cut and fill stopes at Detour Lake Mine', Proceedings of the CIM 93rd Annual General Meeting, Canadian Institute of Mining, Metallurgy and Petroleum, Westmount, QC, paper no. 142.

Lunder, J 1994, 'Hard rock pillar strength estimation an applied empirical approach', Master of Science thesis, University of British Columbia.

Mathews, KE, Hoek, E, Wyllie, DC \& Stewart, S 1981, Prediction of stable excavation spans for mining at depths below 1,000 metres in hard rock / Golder Associates, CANMET Library \& Documentation Services Division, Vancouver.

Milne, D 1997, 'Underground design and deformation based on surface geometry', PhD thesis, University of British Columbia: Vancouver.

Milne, D \& Pakalnis, R 1997, 'Theory behind empirical design techniques', Proceedings of the 12th colloque en controle de terrain de l'Association Miniere du Quebec, Val d'Or, Quebec.

Nickson, SD 1992, 'Cable support guidelines for underground hard rock mine operations', Master of Science thesis, University of British Columbia.

Potvin, Y 1988, 'Empirical open stope design in Canada', PhD thesis, University of British Columbia.

Rauert, NS 2012, 'Wallaby Deeps - from the optimal opportunity to reality', Proceedings of the Narrow Vein Mining Conference, The Australasian Institute of Mining and Metallurgy, Melbourne, pp. 207-214.

Villaescusa, E 2004, 'Quantifying open stope performance', in A Karzulovic \& M Alfaro (eds), Proceedings of the International Conference and Exhibition on Mass Mining (MassMin 2004), Instituto de Ingenieros de Chile, Santiago, pp. 96-104. 